\title{
Data-driven business model development - insights from the facility management industry
}

\author{
Bartosz Marcinkowski and Bartlomiej Gawin \\ Department of Business Informatics, University of Gdansk, Sopot, Poland
}

\begin{abstract}
Purpose - One of the leading factors that shape product and service delivery are data collected in databases and other repositories maintained by companies. The transformation of such data into knowledge and wisdom may constitute a new source of income. This paper aims to explore how small/medium-sized enterprises (SMEs) advance their business models (BMs) around data to handle data-driven products and how this contributes to their innovativeness and performance.
\end{abstract}

Design/methodology/approach - To investigate the phenomenon, the as-is BM of a multinational SME was mapped and its limitations were revealed through a qualitative study. The BM canvas was used. Then the data-driven approach was innovated within the facility management (FM) industry, where a high volume of operational and sensor-based data being collected creates added value in terms of new data-based products. Findings - A data-driven business model (DDBM) blueprint for the FM industry that supports the need to complement service-driven operations with the data-driven approach is delivered. Enhanced BM equips a facility manager with additional managerial tools that enable decreasing property utilization costs and opens up new opportunities for generating revenue. This paper drafts the way to evolve from service to data-driven business and point out the attitudes that managers should adopt to promote and implement DDBM.

Practical implications - The DDBM constitutes a guideline that supports FM organizations in focusing their activities and resources on generating business value from data and monetizing data-driven products.

Originality/value - The research expands knowledge regarding BMs and their evolution. The gap regarding the DDBM innovation within the FM industry is filled.

Keywords Business model innovation, Big data, Facility management, Data-driven business model, Transition economy

Paper type Case study

\section{Introduction}

Modern companies worldwide introduce technology-based innovations not only to streamline their business operations and increase competitive advantage - but also to carve

(C) Bartosz Marcinkowski and Bartlomiej Gawin. Published by Emerald Publishing Limited. This article is published under the Creative Commons Attribution (CC BY 4.0) licence. Anyone may reproduce, distribute, translate and create derivative works of this article (for both commercial and non-commercial purposes), subject to full attribution to the original publication and authors. The full terms of this licence may be seen at http://creativecommons.org/licences/by/4.0/legalcode

This study was supported by the National Centre for Research and Development (PL) competition for micro, small and medium enterprises that have received the Seal of Excellence in SME Instrument competitions, phase II (Horizon 2020). Grant number POIR.01.01.01-00-0003/19. An early concept for research design along with a preliminary literature review was presented at the ICTM conference, Wroclaw, Poland. Author Contributions: conceptualization, B.M.; methodology, B. G.; investigation, B.M. and B.G.; validation, B.G.; original draft preparation, B.G.; review and editing, B.M.; visualization, B.M.; supervision, B.M.; funding acquisition, B.G. 
out new markets (Wang and $\mathrm{Xu}, 2018$ ), meet policies put in place by governments and various regulators, as well as make their businesses more sustainable. Companies that obtain higher technological innovation efficiency are reported to be among those that achieve the highest growth rates (Martínez-Alonso et al., 2019). As maintenance of the built environment is concerned, it is bolstering the energy efficiency of buildings, systems and devices through telemetry based on the Internet of Things and data analytics that is one of the leading technology-related trends nowadays (Konanahalli et al., 2018). It not only equips an interested company with instruments necessary to expand further in the era of rising energy carriers' prices through eliminating energy waste; it also exerts a positive impact on the environment that cannot be brought down to positive publicity.

When considering company-wide technological innovation, one must bear in mind that digitalization is not curbed to isolated projects; rather, entire business models (BMs) shift considerably toward digital environments (Kraus et al., 2019). Businesses originating from emerging/transition economies face unique challenges and conditions regarding technological innovation (Bala and Feng, 2019) - in particular when they have global ambitions. The necessity to abandon imitation strategy (that proved effective in earlier stages of multi-nationalization) and radically re-structure their BMs puts such businesses at a double disadvantage. Not only entering rapidly into remote markets using highcommitment strategies such as acquisitions - and therefore breaking significant entry barriers - is often required (Marchand, 2018), but companies from emerging/transition economies tend to lag behind the competition from developed ones with respect to the maturity level of information technology (IT) (Keszey, 2017), as well as capital.

It is Big Data that might be considered one of the leading technologies behind rolling out complimentary services and securing additional revenue streams by a company. It enables organizations to establish data analytics and to integrate data in real-time from a variety of sources (Bange et al., 2015) with supporting information-sharing and decision-making in mind (Mandal, 2019). With the availability of volume, velocity, variety and data veracity (4 V), new business opportunities are presented (Erevelles et al., 2016). Mature companies such as Apple and Amazon - focus on business model innovation (BMI) around Big Data to approach their customers with new services and products, as well as to secure additional revenue streams (Lokitz, 2018). The concept of a data-driven business model (DDBM) is built around data as a product - it lays out benefits for users of data-based services and introduces methods for managing (i.e. promoting, pricing, sale and delivery) of such products (Bange and Derwisch, 2016). Attention to BMI has been increasing throughout business practice and research (Amit and Zott, 2012) for some time. However, leveraging Big Data and constructing DDBMs invariably remains a challenge for many companies. Facility management $(\mathrm{FM})$ is a service-oriented profession that encompasses multiple disciplines to ensure the functionality of the built environment by integrating people, place, process and technology (IFMA, 2012). Property owners usually outsource the bulk of maintenance activities to external business partners. Related sources describe BMs within this industry in terms of a relationship between a property owner and an FM services provider - and BMI is perceived as improving FM processes, configuring organizational structures, day-to-day management, risk management and cost-effectiveness (Nardelli and Rajala, 2018; Jensen, 2011).

We observed the lack of proficiency within FM regarding BMI focused on Big Data, information, knowledge and wisdom - all of which are being collected in the structures and systems of FM companies during service processes executions. Hence, upon taking advantage of the feedback regarding the initial research design (Gawin and Marcinkowski, 2017a), a couple of research questions have been posed: 
RQ1. What is the role of Big Data in BMI within the FM industry?

Facility

RQ2. What components of a DDBM might be considered FM-specific?

Our research focuses on how FM companies advance their BMs on account of Big Data collection, processing and analysis. The goal of the study is to develop a reference DDBM in which a considerable share of FM organization's revenues come from knowledge and wisdom captured in a systematic and orderly manner across the company's IT ecosystem.

The subsequent section of the manuscript establishes a research background for our study in Section 2. Then, the research approach, setting and methods used are provided in Section 3. Findings of the study are discussed next: the as-is BM of a multinational FM company is addressed, its deficiencies revealed, ensued by conceptualizing a DDBM framework that has been put in practice as a target model in Section 4. Empirical validation of the DDBM is introduced in Section 5. Subsequently, the theoretical and practical implications are discussed along with the limitations of the study in Section 6, followed by conclusions in Section 7.

\section{Literature review}

\subsection{Data and big data}

Data and business intelligence (BI) solutions are recognized as a driving force behind not only contemporary global organizations - but for small/medium-sized enterprises and startups as well (Rotella, 2012). Yet, not all data is valuable. To make efficient data-based decisions, data must come in digital form, be arranged, cleared of incorrect records and data gaps, integrated, as well as provided to decision-makers at the right place and time without undue delay - just to name a few preconditions. As data becomes more refined, companies begin to recognize it as an enterprise-wide asset, whereas employees and managers start to work with it more instinctively. Bulks of data in business are constantly increasing. A notion of Big Data refers to data that comes in enormous volumes (Bange and Derwisch, 2016), in many different formats and forms, while being generated (and inevitably also processed) with high intensity - and not without risk of inaccuracies, gaps and other factors that potentially reduce the reliability of data. Nowadays, Big Data became a tremendously vast concept that includes different subcategories and specifics, which are characterized by different technical and regulatory challenges (Favaretto et al., 2020). While Big Data tend to rely heavily on unstructured data sources, companies setting up BI solutions that take advantage of Big Data repositories to lean toward database-related sources - just to mention Enterprise Systems and their sub-classes.

Dissemination of Big Data has the potential to revolutionize the way companies set up their BMs and build their competitive advantages to define their advantages over competitors. According to McAfee and Brynjolfsson (2012), productivity and profitability indicators of companies that inject Big Data and analytics into their operations are reported to be $5 \%$ to $6 \%$ higher than those of their peers. A study effectuated among 232 mediumsized and large UK manufacturing companies by Cao and Duan (2017) demonstrated that top-performing enterprises are 5.31 to 7.56 times more likely to make data-driven decisions than bottom-performing ones; on top of that, top-performing companies - in contrast to their peers - have a statistically significant correlation between descriptive analytics and organizational strategy. 
JFM

19,2

\subsection{Business models}

BMs play a fundamental role in attempts to commercialize the technology, and thus achieve its objective economic value (Chesbrough, 2010). As pointed out by Mazzarol et al. (2018), a BM might be considered an endlessly evolving conceptual tool that draws together the logic behind a business venture. It depicts how products, services, image, distribution, organization of staff and the operational infrastructure are uniquely put together by a company to generate value for customers (Chesbrough and Rosenbloom, 2002). As classified by Zott et al. (2011), research on BMs generally falls into three major categories:

(1) e-business and the use of IT in organizations;

(2) strategic issues - such as value creation, competitive advantage and performance of a company; and

(3) innovation and technology management.

The extant body of knowledge from BM research is focused on more generic BM frameworks (Johnson et al., 2008; Bouwman et al., 2008). According to Chesbrough and Rosenbloom (2002), BMs articulate value propositions, identify market segments and define value chains within companies. For instance, the framework of Johnson et al. (2008) delivers a value proposition based on four interlocking components - customer value proposition, profit formula, key resources and key processes. The Service/Technology/Organization and Finance (STOF) model discussed by Bouwman et al. (2008) features services, technology platforms/architecture, ecosystems, as well as finance and risk-related uncertainties. On the other hand, the practitioner-oriented BM canvas consists of nine building blocks, namely, value proposition, key processes, key resources, key partners, customer relationships, channels, customer segment, revenue streams and cost structure (Osterwalder and Pigneur, 2010). Hartmann et al. (2016) attempt generalizing identified static BM frameworks in a systematic manner, stressing that there is no general agreement on BM dimensions - and leaving some significant Canvas concepts aside.

In the digital age, most contributions refer to BMs that rely on data. Bange and Derwisch (2016) highlight four challenges in implementing data products: a BM in place, marketing and sales, delivery of data-based products, as well as data management. On top of that, Batra (2017) reports that the target group of business users who demand access to superior predictions escalates and analytics becomes more interactive. Three categories of BMs built around Big Data are distinguished by Lokitz (2018) based on their value propositions and customers: data, information and answers as services.

\subsection{Business model innovation}

Björkdahl and Magnus (2013) consider BMI in terms of a new integrated logic of value creation and value capture, which can comprise a new combination of novel and old products or services, as well as changes in both market position and process management of a company. Amit and Zott (2012) seek BMI in enhancing current BMs with revelatory activities, taking advantage of original linkages within activity structure and changing one or more parties that perform any of the existing activities. As pointed out by Lindgardt et al. (2009), BMI may be considered a multidimensional and orchestrated set of activities that lead to the re-invention of at least two BM components to deliver value in new ways. As BMI positively mediates the relationship between integrative capability and company performance, it is up to managers to take advantage of it to improve company performance and understand that BMI's role varies across different business strategies (Pang et al., 2019). Barton and Court (2012) highlight the milestones of putting a data-driven strategy in place: 
- choose the right data and sources using IT support; then

- build models that predict and optimize business outcomes; and

- transform the capabilities of the company.

On the other hand, Liu and Bell (2019) strongly stress the importance of the following factors in the BMI process effectuated in emerging/transition economies:

- development of a strong and loyal customer base;

- active customer feedback to ensure the product meets customer needs and to avoid expensive mistakes going forward;

- extension of the value network to ensure finance is available to allow both product development and BM development; and

- development of the network to take advantage of collaborative opportunities.

Making the most of Big Data translates to having a definite BM and placing it right in the center of the business. FM industry, to date, seems to undervalue the necessity of taking advantage of the benefits that data-orientation provide. For instance, Nardelli and Rajala (2018) discuss the evolution of BMs within FM, focusing on BMI - yet their research stresses the aspect of inter-organizational collaboration across different phases of the innovation process, leaving data itself aside. A report for the Royal Institution of Chartered Surveyors clearly indicates the need for gathering, processing and taking advantage of knowledge within the FM industry (Mehdi, 2018). That being said, both monetization of data-based products and fitting such products into FM BMs are neglected by the report. Similarly, a report jointly branded by the International Facility Management Association and the Royal Institution of Chartered Surveyors (Ware et al., 2017) says a lot about adapting BMs to take advantage of new technologies but provides neither real-life examples of such changes nor guidelines for introducing them.

The BMs used to-date in numerous industries including FM (Bouwman et al., 2008; Johnson et al., 2008; Nardelli and Rajala, 2018; Hartmann et al., 2016) feature technological components or abstract constructs that potentially bring together systems and applications of both transactional and analytical nature. However, the fact that in the era of Big Data and $\mathrm{BI}$, data is the fuel supplying organizational knowledge and wisdom necessary for agile business operations seems to be neglected. Then, although reports from international organizations confirm that FM BMs shall evolve toward data management, it is challenging to identify best practices or real-life applications of reference models that may constitute the basis for tailor-fitting. Therefore, we consider the low level of FM industry maturity regarding the development of DDBMs combined with the lack of established practices for implementing data-based products within this industry to be a non-trivial research gap to be explored.

\section{Research approach}

The study follows a qualitative approach: a single-unit case study was conducted in an FM company of multinational scope, headquartered in Poland. Poland constitutes an economy that transitioned toward market-driven by abruptly discontinuing central planning at the expense of a temporary economic collapse and the necessity to build its external presence from scratch. The company selected for the study, SESCOM Group, is one of the few enterprises representing the FM industry that openly voice the desire to reach data-driven status and take specific actions to do so. With over a decade-long experience, the company focuses on its proficiency in delivering reliable building maintenance, energy efficiency 
JFM

19,2

134

management and technical service solutions to its European business partners. Moreover, it constitutes the lone FM company in Poland that is a beneficiary of a grant directed at developing an analytical platform, thus blending into the essence of the research approach selected. As a part of the Horizon 2020 program, SESCOM has performed a feasibility study for the SES-BI - business intelligence platform for energy saving and smart facility management projects. Following its conclusions, to extend the company's offerings for data management, analytics and delivering energy efficiency-targeted solutions, the as-is BM must be changed from service-driven to data-driven.

As pointed out by Yin (2017), the case study method features a thorough investigation of a contemporary phenomenon within its real-life context through empirical research, and single-case designs assign them roles in applying, testing or building theory. As we were not longing for generalization outside the FM industry and attempted to trace a potential path of innovation for other companies within this industry, we took advantage of single-case design benefits - just to mention its ability to fine-tune the level of detail to a particular case (Eisenhardt and Graebner, 2007) and capability to assign sufficient observation time to study a complex case in-depth (comp. Gerring, 2004). Because of the aforementioned benefits, single-unit case studies were successfully applied to shed a light on typical or extreme cases in both corporate (Molka-Danielsen et al., 2017) and national (Gunawong and Gao, 2017) contexts, which strongly affect our study. Figure 1 shows the line of research that has been adopted and carried out successfully.

To gather viable research data, we carried out a series of three workshops that lasted approximately $6 \mathrm{~h}$, at weekly intervals. Six members of the company's top-level management were involved in the process. Each participant held the position of director with at least 24 months of experience in the position and represented a different area of business, as presented in Table 1. Every workshop engaged a pair of researchers. One interviewer was tasked with the dialog itself, whereas the other was responsible for detecting missing feedback or redundant content on-the-fly. After each question, the roles were reversed. Subsequently, the transcripts were coded using NVivo: a software tool supporting qualitative studies. The open coding process was used with a per-paragraph level of detail (Böhm, 2004).

The first workshop enabled us to capture as-is BM of SESCOM Group and later explore its limits and opportunities in terms of introducing data-based products. To ensure adequate research rigor, the structured content of the first workshop was allocated to nine research nodes as defined by Osterwalder and Pigneur (2010). The management provided the research team with two vital secondary sources: a feasibility study (internal assessment of

Figure 1.

Line of research

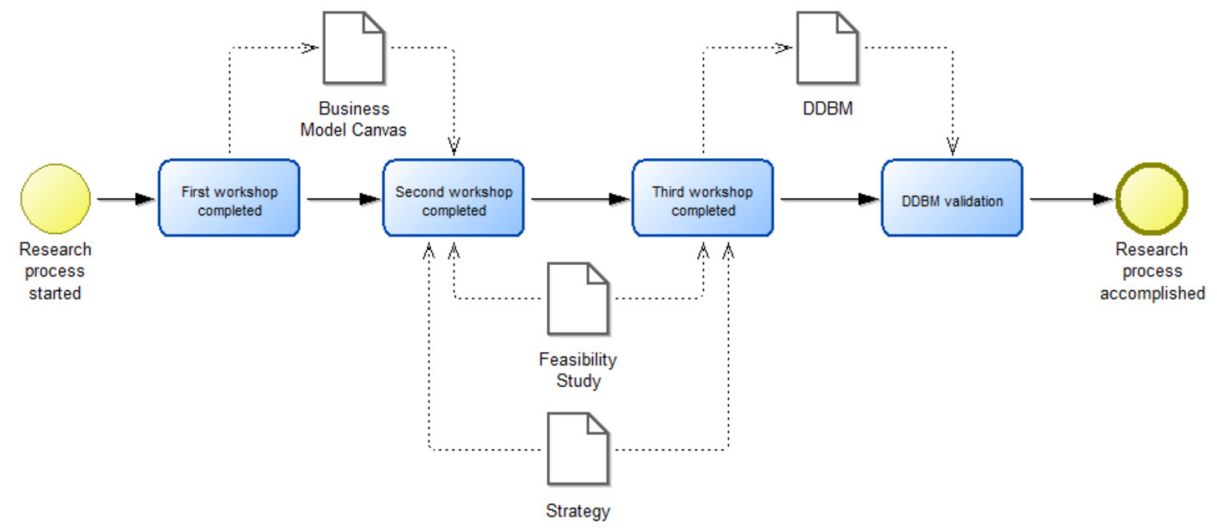




\begin{tabular}{|c|c|c|}
\hline Business area & Primary responsibilities & ity \\
\hline Marketing director & $\begin{array}{l}\text { - Market analysis and trend prediction } \\
\text { - Brand development } \\
\text { - Maintaining the overall image of an organization } \\
\text { - Preparing marketing campaigns } \\
\text { - Organizing events } \\
\text { - Putting communication and marketing strategies in place }\end{array}$ & 135 \\
\hline 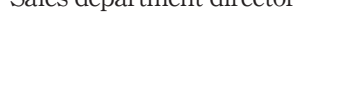 & $\begin{array}{l}\text { - Identifying the business needs of the customer base } \\
\text { - Supervision over the achievement of sales targets } \\
\text { - Conducting sales negotiations }\end{array}$ & \\
\hline $\begin{array}{l}\text { Operating department director } \\
\text { (Poland) }\end{array}$ & $\begin{array}{l}\text { - Ensuring efficient and safe working environment } \\
\text { - Monitoring quality of service indicators }\end{array}$ & \\
\hline & $\begin{array}{l}\text { - Enforcing legal requirements, standards, policies and best practices } \\
\text { - Managing day-to-day FM operations }\end{array}$ & \\
\hline IT department director & $\begin{array}{l}\text { - Aligning IT strategy with business goals of an organization } \\
\text { - Planning, building, maintaining and overhauling IT infrastructure } \\
\text { - Managing software development projects } \\
\text { • Ensuring availability and security of IT services } \\
\text { - Integrating both in-house and external IT solutions }\end{array}$ & \\
\hline Finance department director & $\begin{array}{l}\text { - Financial planning and fundraising } \\
\text { - Managing budget utilization } \\
\text { - Enforcing accounting policies and conducting internal audits } \\
\text { - Carrying out feasibility studies and improving returns on investments }\end{array}$ & $\begin{array}{r}\text { Table } 1 . \\
\text { Participants of the } \\
\text { workshops }\end{array}$ \\
\hline
\end{tabular}

the potential for collecting and analyzing data in the organization) and a detailed description of the company's strategy. These were used across the second/third workshop.

The current BM canvas of SESCOM Group established as a result of the first workshop was thoroughly discussed during the second workshop. The managers have assessed it and proposed minor enhancements. Brainstorming that captured advantages and disadvantages of the as-is BM directly translated to developing the DDBM.

To elaborate on the DDBM, the third workshop featured approaching the participants with a questionnaire covering six open-ended questions (Brownlow et al., 2015):

(1) What do we want to achieve by using Big Data?

(2) What is our desired offering?

(3) What data do we require and how are we going to acquire it?

(4) In what ways are we going to process and apply this data?

(5) How are we going to monetize it?

(6) What are the barriers to us accomplishing our goal?

The contents of the final workshop were, again, coded. The credibility of the analysis was enhanced through:

- independently coming up with the initial structure of the research nodes by each researcher;

- triangulating feedback with secondary data: internal documents, data analysis project cards from the past, as well as external (customer-bound) and internal (staffbound) data analysis reports; and

- cross-checking individual steps of the process. 
JFM

19,2

136

\section{Findings}

\subsection{As-is business model}

The BM canvas was used to depict how SESCOM Group generates, delivers and captures value. It consists of nine main building blocks and enables increasing the understanding of how a given business operates. The building blocks - customer segments, value proposition, customer relationships, channels, key activities, key resources, key partners, cost structure and revenue streams - may be allocated to three business areas, as presented in Figure 2.

First of the building blocks under analysis, i.e. customer segments determine various classes of retail organizations that SESCOM aspires to reach and serve. We distinguish six customer segments, as they require different types of relationships and they are keen on paying for distinct aspects of the offering, namely, supermarkets, small shops, bank branches, offices, base receiver stations for mobile operators and petrol stations. It is having a network of facilities across Poland (in many cases - across other European countries as well) that is the common feature of these customers.

In turn, the value proposition represents the portfolio of services provided by the SESCOM that creates value for a given customer segment. For supermarkets, the company offers a comprehensive FM service that includes caretaking of entire buildings, various installations and systems. Other customers do not require such a comprehensive offer and limit requested FM activities to IT services, maintenance of hardware classified as heating, ventilation, air conditioning and refrigeration (HVACR), as well as minor repair work (e.g. repairing furniture, replacing light sources or painting rooms). Common quantitative VPs include consolidated knowledge (collection, analysis and interpretation of data aimed at controlling processes, costs and revenue planning), response times in line with service level agreements, efficient use of resources, allocating funds for increasing business efficiency, technical support provided in 24/7 mode.

Types of relationships that SESCOM gets into with certain customer segments are described by the customer relationships of the BM canvas. For each segment, we identified personalized relationships (each client is approached individually by the contract manager) and automated interactions through the SES support platform (the proprietary IT solution that supports managing service processes). SESCOM's strategy is focused on building longterm relations with customers based on personal and IT-supported channels.

Another building block, i.e. channels, depicts how the company reaches and communicates with its customer segments to deliver the value proposition. The preferred contact channel is built around the SES Support platform - which in this case acts as an IT tool that aggregates information about processes. Customers use a web browser to initiate processes and to observe their progress. To facilitate contact with customers, SESCOM Group has developed a mobile version of the platform. While the SES Support enables building relationships at the operational level, the group delivers industry content through mailing, corporate website, newsletter and content-related whitepapers. There are also some activities undertaken, aimed at building direct relationships, e.g. sales activities, conferences and seminars.

Figure 2.

Canvas BM framework

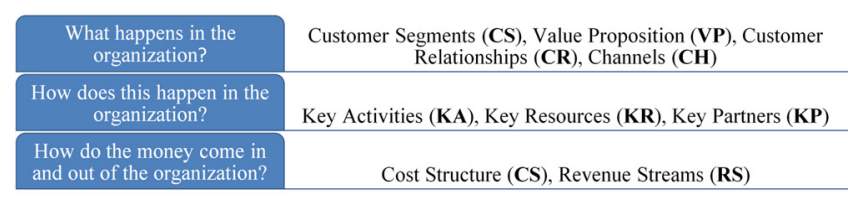


Main actions a company must undertake to make its BM work constitute key activities. To reach markets, as well as create and offer value propositions, SESCOM builds and maintains relationships with customers. Key is direct meetings with the clients on different levels, namely, technical, organizational, sales and strategy. Moreover, the company constantly monitors global and European trends in the FM industry, namely, technologies, product development and organizational challenges. To advance its BM, SESCOM executes research and development $(\mathrm{R} \& \mathrm{D})$ projects and constructs prototypes of analytical tools. To generate revenue, the company constantly pursues its core FM processes.

In turn, key resources describe the main assets within a company that makes a BM work. SESCOM divides its key resources into four parts:

(1) physical resources (computer hardware and software, vehicles, office equipment, tools);

(2) intellectual resources (brands, partnerships, proprietary knowledge, years of experience and know-how);

(3) human resources; and

(4) financial resources.

Two proprietary IT platforms are of particular importance: the SES Support (to manage FM processes) and the SES Control (to manage energy efficiency).

The key partnerships building block delineates the network of partners and suppliers that are key to maintaining the BM. Over a decade, the group has established a grid of technical partners - who, throughout entire Europe, provided services and maintenance tasks. Key partners include suppliers of spare and consumable parts for devices (e.g. HVACR systems) as well. Within IT/R\&D projects, the company cooperates with start-ups and involves external experts who represent various professions and specializations (e.g. data scientists, lawyers and digital designers) to a considerable degree.

$\mathrm{BM}$ canvas's cost structure generalizes total costs incurred to operate a BM - for example, pertained to creating/delivering value, perpetuating customer relationships, generating revenue and focusing on long-term customer relationships. In SESCOM, cost structures can be divided into fixed costs (monthly salaries, rent for office spaces, license fees) and operational costs - OPEX (electricity bills, expenditure regarding maintenance of machinery/cars/tools, marketing).

Finally, revenue streams describe in what way a company shall generate cash flows from each customer segment. The revenue stream has to take into account how much customers will be willing to pay for the value the company delivers. The company has a single revenue stream that bundles recurring revenues from on-going payments. It includes revenues from property maintenance, energy efficiency management and providing basic data analytics to customers.

\subsection{Deficiencies of the as-is business model}

Reflection on the BM canvas and the feasibility study disclosed that the company had access to multiple data sources indeed, but was unable to facilitate data products in terms of an added value:

We collect data from many sources. We collect them in IT systems, but we are not able to successfully process them and use the acquired knowledge (IT Department Director).

As-are commercial offerings do not include mature data products; key activities still required unique selling propositions design: 
JFM

19,2

138

Conclusions and recommendations from processed data should constitute a separate revenue stream for the company (Sales Department Director).

SESCOM pinpointed many factors that have a disruptive effect on the core processes of most FM companies. Those include, but are not limited to, rising costs, declining revenues, competitive pressure - but also increasing customer requirements in terms of counseling, data analysis services behind maintenance, access to information, costs forecasting, designing FM key performance indicators and budget monitoring:

Our clients not only expect technical work to be carried out in commercial facilities - they expect advice, recommendations, support in budget planning, as well as predicting equipment failure rates and forecasting electricity consumption. This is difficult to achieve without analyzing the data (Operational Directors).

Ultimately, it can be safely said that activities effectuated throughout the early stages of the current study went beyond increasing the awareness of top-level management regarding the impact that digital change has on traditional BMs. Company-specific barriers and facilitators readjusted during the second workshop paved the way to elaborating and finetuning the DDBM blueprint for the FM industry.

\subsection{SESCOM's data-driven business model}

Based on the feedback collected during the last workshop, the DDBM blueprint was delivered. Thus, a platform that stimulates SESCOM to become data-driven was established. The DDBM was put into practice and remains a subject of continuous improvement and fine-tuning based on validations. Figure 3 introduces an abstract representation of the integrated DDBM framework, the components of which are further elaborated in Table 2.

SESCOM's DDBM is based on the conviction that data products take traditional FM to a higher level and thereby increase the revenues of the company affected by it. DDBM integrates five high-level components. Four of them (sale proposition design, data management policy development, marketing strategy development and BICC development) directly shape the data-based revenue approach development (solid line). At the same time, soft interactions (i.e. coordination, cooperation, promotion) take place among the four influencing factors. Therefore, the dashed lines point out what specific actions occur between these nodes.

Both the development of new commercial offers and making the existing ones more attractive is required:

We have to present the processed data reports, conclusions and recommendations as our flagship product, as a mechanism necessary for effective (Marketing Department Director).

Figure 3.

Overview of SESCOM's DDBM

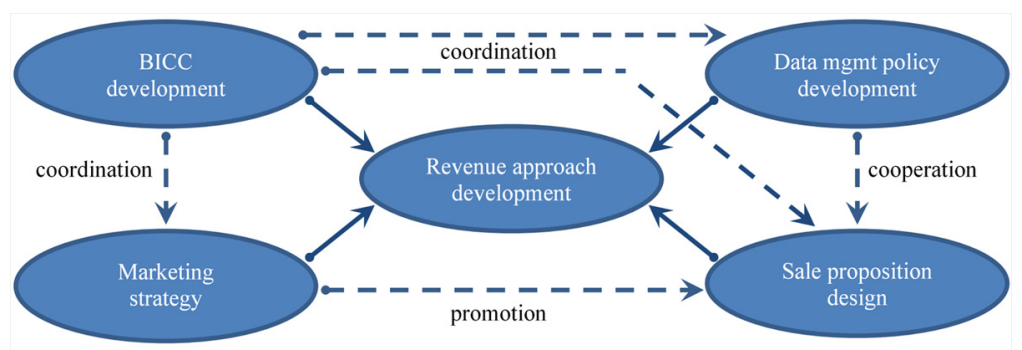




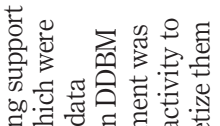

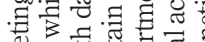

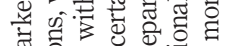

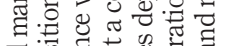

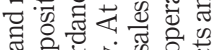

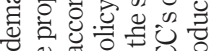

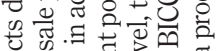

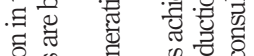

을

还

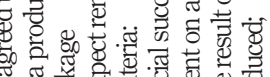

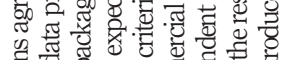

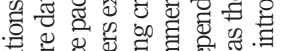

-

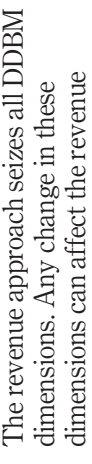

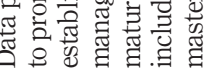

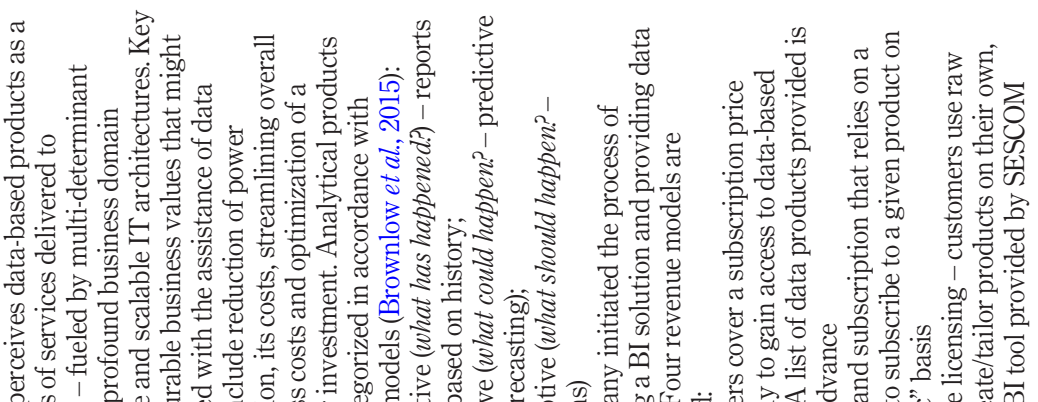

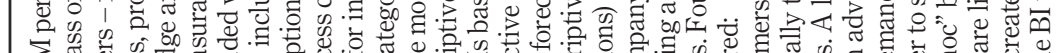

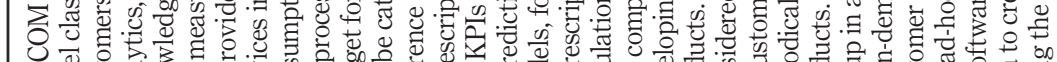

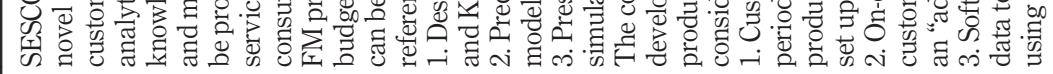

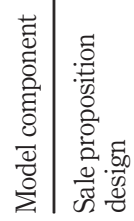

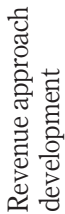

Table 2. 
JFM
19,2

140

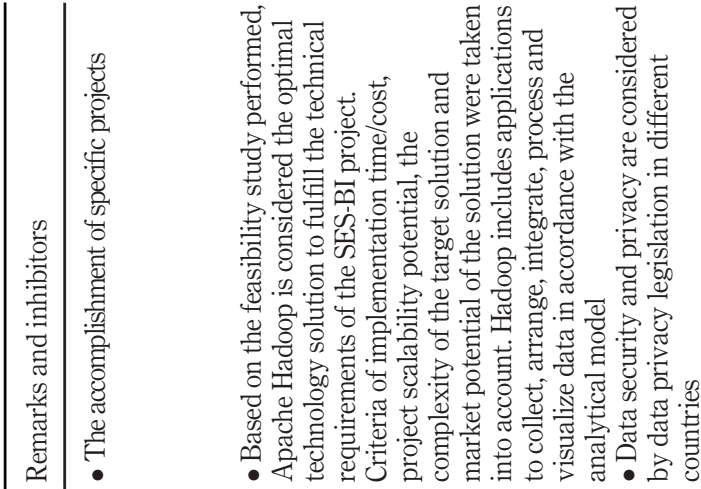

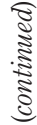

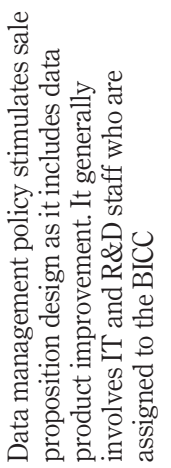

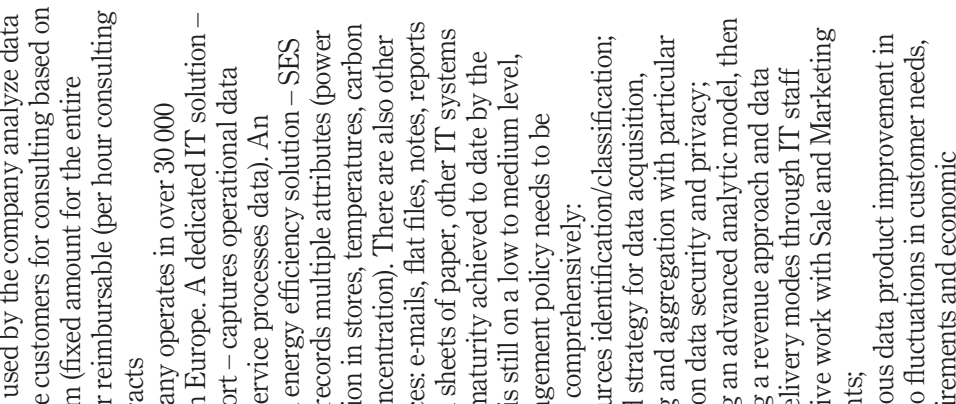

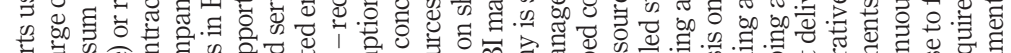

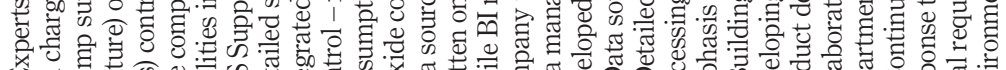

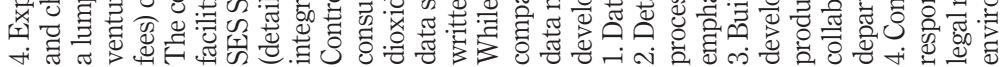

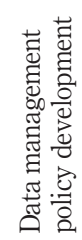

Table 2. 


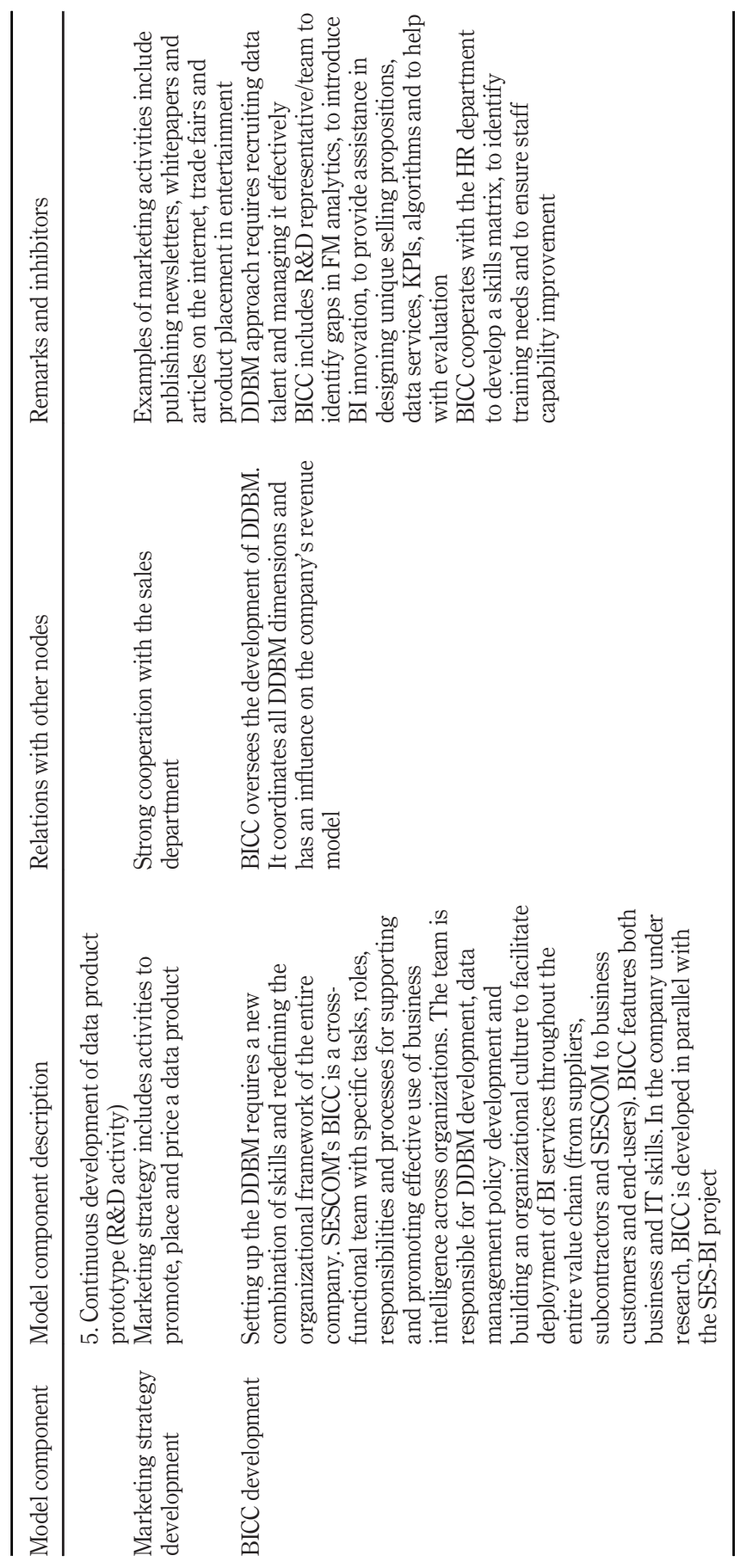

Facility management industry

141

Table 2. 
JFM

19,2

The role of marketing and sales is to convince the customers of the company that every process may be considered a "data-driven decision-making" measure in formulating an FM approach. Key questions regarding facility maintenance, budget planning and reducing power consumption generally require inter-departmental data sources and joint effort of individual departments in posing hypotheses and mapping activities via algorithms. It is crucial to ensure that customers benefit from the proposed innovation if SESCOM wants to truly introduce digital change and develop the DDBM.

\section{Validation of the data-driven business model}

The DDBM blueprint was field-tested during the implementation of the contract signed with a corporate customer that runs its business globally. The customer owns service/ commercial buildings around the world, several dozen of which are located in Poland. The customer enlisted support in data analysis from multiple sources. In particular, substantial support in managing energy efficiency was required, and the main goal of putting the components of DDBM into work from the customer's point of view was to reduce the overall cost of electricity consumption across facilities. SESCOM wanted to check whether the DDBM can deliver developing and implementing efficacious recommendations to reduce electricity consumption. SESCOM created a marketable data analysis/processing product from this consultancy.

Negotiations with the customer enabled the group to gain full access to data sources required to fulfill the contract (just to mention sensor data, invoice data, weather data, number of transactions, building surfaces/volumes) and to include all DDBM components in this contract. As a consequence, a layer of detail shown in Table 3 was added to the individual components of the model and it was confirmed that the specific determinants on the customer's side did not affect the relationships between the model nodes.

For the purposes of analyzing feedback on the implementation of the contract, the research team was provided with access to minutes of meetings, working notes and nonfinancial contractual details. A single researcher was delegated to participate in selected internal meetings. The validation revealed that SESCOM ought to streamline the operation of its new BM with respect to its sales department performance, public relations and marketing performance. Non-technical staff needs to understand products made possible by DDBM and promote them more effectively. IT tools - both dedicated to collecting data and processing it - require constant improvement. Possible IT infrastructure extensions are being analyzed, and new predictive algorithms are accounted for. Additionally, the management of the company feels that the Business Intelligence Competency Center is lacking a Facility Manager, who could interpret certain data concerning the condition and construction of buildings, as well as individual systems and hardware.

The customer itself took advantage of the products delivered (analyzes and reports) and began implementing recommendations by launching a savings program scheduled to last for three years. Feedback gathered to date points at the legitimacy of adopting the revenue approach in place through introducing shares in the savings generated in exchange for a reduction in the subscription fee.

\section{Implications and limitations}

Our research confirms that Big Data can indeed be considered a resource with a real potential to drive the radical business transformation within a given industry in the contemporary entrepreneurial landscape. Companies develop new BMs in hopes of generating additional business value through extraction, refinement and ultimately monetizing data (Hartmann et al., 2016). While related studies discuss DDBMs in distinct 

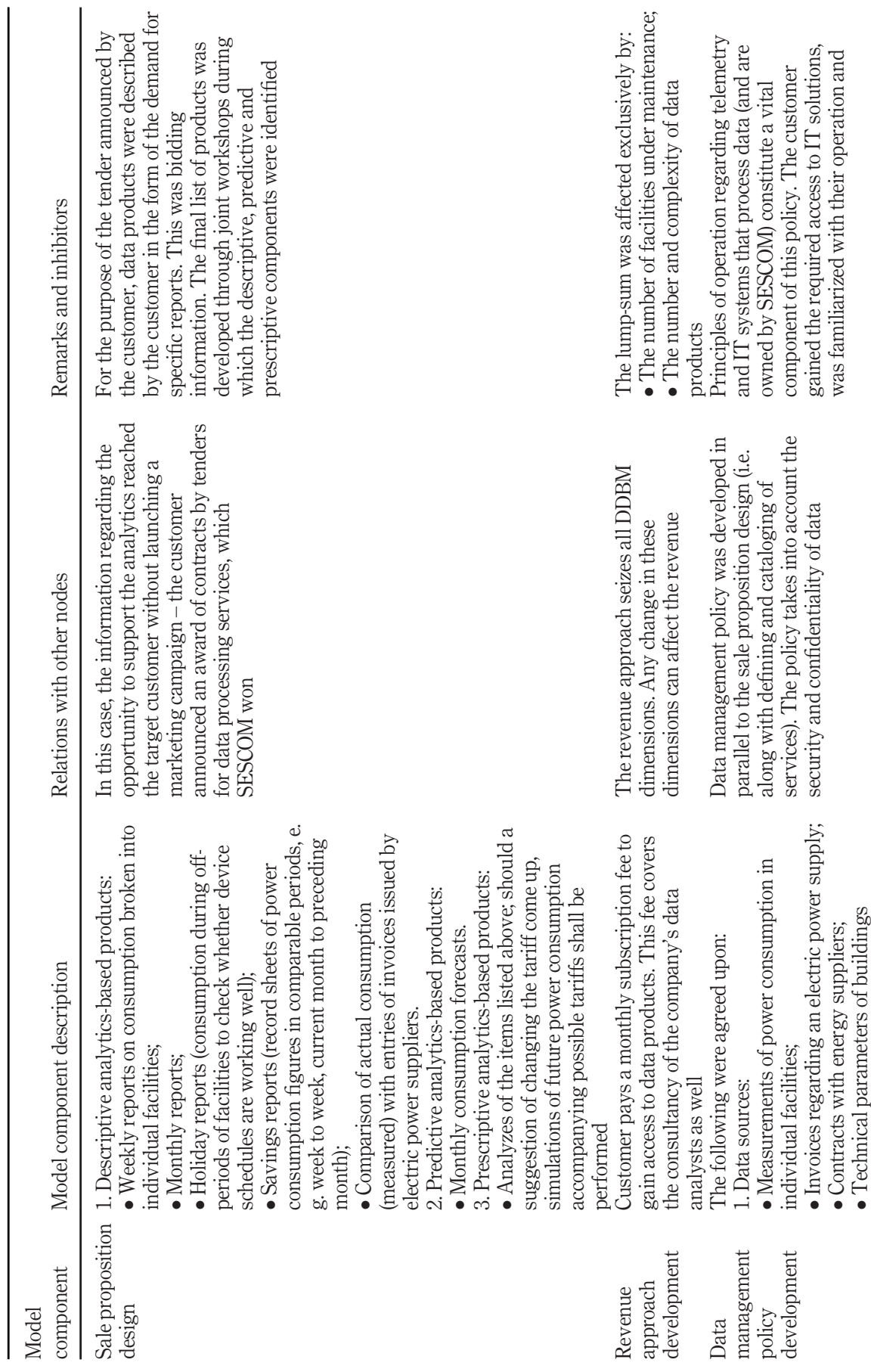

Facility
management
industry

Table 3. Validation of the reference DDBM blueprint adaptation to an actual contract 
JFM
19,2

144

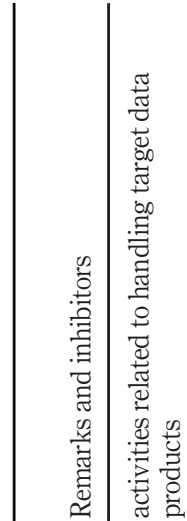

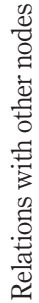

Table 3.

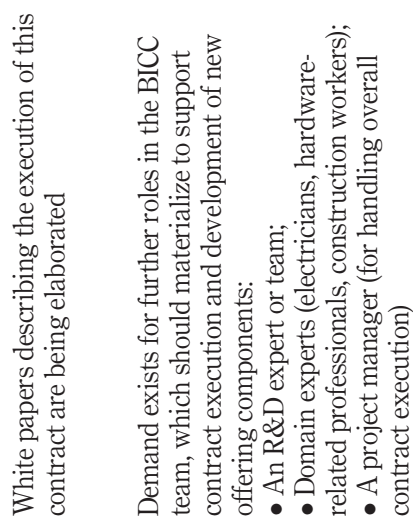

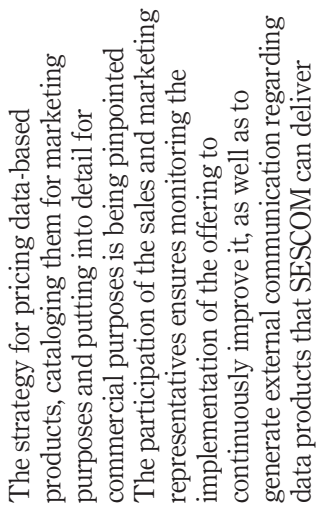

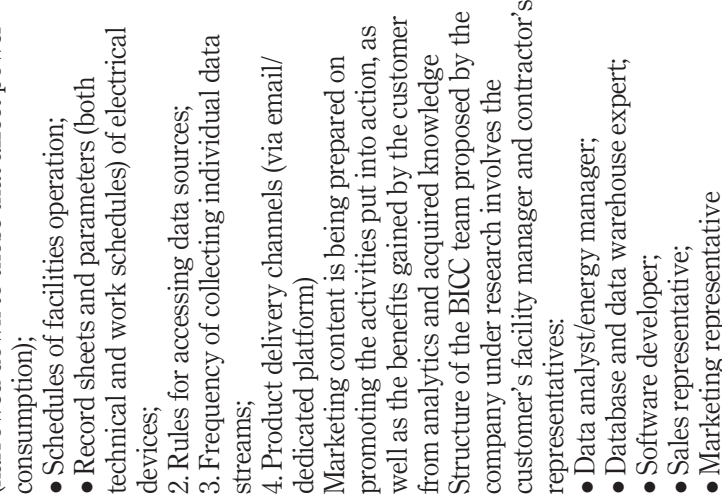

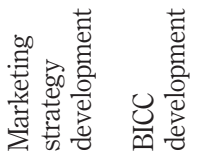


business areas (Zaki et al., 2015; Smith et al., 2015) that typically are based on similar frameworks (Brownlow et al., 2015; Hartmann et al., 2016), this contribution takes advantage of high volumes of operational and sensor-based data collected by FM companies (Gawin and Marcinkowski, 2017b). The availability of such data unleashes BMI potential within the FM industry by providing an added value. This value is manifested in terms of brand-new data-based products, which enable decreasing property utilization costs, limiting energy waste and finally deliver more sustainable working environments for customers who to-date were confined to traditional FM services. Thus, Big Data's $4 \mathrm{~V}$ specificity has been successfully supplemented with the fifth $\mathrm{V}$ that was postulated across academic contributions and reports: value.

The trends acknowledged by internationally-recognized FM organizations, the potential of data-based products recognized by the European Commission, as well as the positive feedback from the DDBM validation indicate that companies must be able to identify, develop and continuously improve four areas: sale proposition, revenue approach, data management policy and marketing strategy for data products. On top of that, the BICC must have a muscle to transform the business, so that data product development/delivery became a relevant factor in the company's vision and long-term strategy as mainstream for designing value proposition and generating revenue. Finally, a common strategy, integrated approach, organizational transformation and cooperation among DDBM areas are needed to capture and synchronize DDBM growth. Our research extends the contribution of Hartmann et al. (2016) by including marketing, promotional and competency elements focused on the production and delivery of data-based products. Following Cheah and Wang's (2017) argumentation that companies must find suitable BMI paths for their development, we indicate the organizational areas that could implement the innovation process of the BM.

The research also contributes to managerial practice. By using the DDBM blueprint, any FM company may follow a step-by-step reference process to build its own DDBM around resources, skills and specific settings within which it operates. Of course, this will not all happen in a single day. Those skills, tools and insights take time and effort to build. To avoid the common trap of DDBM development, managers ought to ensure the alignment of BMI initiatives with the mission of the company. Contracts built around the DDBM proved to be satisfactory for both the company its customers. Applying the DDBM supported several adjustments on the customer side, which led to more efficient and sustainable business expansion patterns. BMI effort discussed in the study comes with an important lesson for enterprises that contemplate establishing their distinctive data product portfolio. Abating traditional methods of remuneration and advertising channels was instrumental in reducing customers' initial costs while maximizing long-term business gains. Relying more on a commission-based revenue approach and preparing an optimal setting for word-ofmouth marketing - which is a natural consequence of successful recommendation-driven projects - ought to be considered instead.

As with any research, some limitations should be considered. To begin with, even companies within FM have slightly different technological capabilities regarding the provision of data-based products. Thus, replicating the workshops throughout industry leaders in various countries could unveil interesting product options and establish a base for comparing developed and emerging/transition economies. Second, acquired knowledge cannot be directly generalized outside FM. High reliance on telemetry and distinctive synergy opportunities in our opinion justify classifying companies representing this industry as extreme cases. Future work features monitoring and tailoring the DDBM blueprint in the real-world setting. Simultaneously, we consider conducting extended research to identify detailed steps to move from a traditional to a data-driven BM in an FM company. 
JFM

19,2

\section{Conclusion}

The study clearly positioned Big Data as an enabling factor for evolving a servicebased BM in place toward a data-driven one. Data-based products are designed to effectively solve perpetual FM problems - such as monitoring power consumption and tracking the lifecycles of devices, systems and buildings - while emphasizing preventive measures at the expense of reactive ones. Because of Big Data in FM, potential issues and inefficiencies might be pinpointed with much greater accuracy and addressed beforehand.

Moreover, the authors established and validated a DDBM framework for SESCOM. We conducted three workshops with top-level managers of the company to provide synergy with a large volume of information that originated from a feasibility study of the BI solution, which was accomplished in the company during a four-month-long period. We built upon the as-is BM of the SESCOM Group that revealed it as a strictly service-oriented company. To address the constraints of the phased-out BM, we proposed five components of DDBM: sale proposition design, revenue approach development, data management policy development, marketing strategy and BICC development. We noticed two innovations in our approach: the significant role of BICC and relationships between model elements. While, usually, the responsibility for data management strategy lies with CDO (Chief Data Officer) as the person at the forefront of an organization's shift toward a data-driven business, our research highlighted the importance of BICC assembled from staff representing the departments in different corporate units. As a multidisciplinary group, BICC manages the BI development project. Analytical competencies evolve as the DDBM matures.

Our research explored strategic issues in the organization and revealed a few elements behind DDBM development. The BMI venture went beyond the wellestablished scope, additionally featuring marketing, promotional and competency elements focused on generating and delivering data-based products. We highlighted the key role of a BICC within BMI and indicated the organizational areas that could take the greatest advantage of innovating business activity. On top of that, we provided a viable DDBM blueprint for an FM company and drafted the way to get from service- to data-driven business.

\section{References}

Amit, R. and Zott, C., (2012), "Creating value through business model innovation", MIT Sloan Management Review, Vol. 53 No. 3, pp. 41-49.

Bala, H. and Feng, X., (2019), "Success of small and medium enterprises in Myanmar: role of technological, organizational, and environmental factors", Journal of Global Information Technology Management, Vol. 22 No. 2, pp. 100-119, doi: 10.1080/1097198x.2019.1603511.

Bange, C. and Derwisch, S. (2016), "Building data products to realize data-driven business models", available at: http://blog-sap.com/analytics/2016/11/21/building-data-products-to-realize-datadriven-business-models (accessed 05 August 2020).

Bange, C., Grosser, T. and Janoschek, N. (2015), Big Data Use Cases. Getting Real on Data Monetization, BARC, Würzburg.

Barton, D. and Court, D., (2012), "Making advanced analytics work for you", Harvard Business Review, Vol. 90 No. 10, pp. 78-83.

Batra, D., (2017), "Adapting agile practices for data warehousing, business intelligence, and analytics", Journal of Database Management (JDM), Vol. 28 No. 4, pp. 1-23, doi: 10.4018/JDM.2017100101. 
Björkdahl, J. and Magnus, H., (2013), "Editorial: business model innovation - the challenges ahead", International Journal of Product Development, Vol. 18 Nos 3/4, pp. 213-225.

Böhm, A. (2004), "Theoretical coding: text analysis in grounded theory", in Flick, U., von Kardorff, E. and Steinke, I. (Eds), A Companion to Qualitative Research, SAGE Publications Ltd, London, pp. 270-275.

Bouwman, H., Faber, E., Haaker, T., Kijl, B. and De Reuver, M. (2008), "Conceptualizing the STOF model", in Bouwman, H., De Vos, H. and Haaker, T. (Eds), Mobile Service Innovation and Business Models, Springer, Berlin-Heidelberg, pp. 31-70.

Brownlow, J., Zaki, M., Neely, A. and Urmetzer, F. (2015), Data and Analytics - Data-Driven Business Models: A Blueprint for Innovation, University of Cambridge, Cambridge.

Cao, G. and Duan, Y., (2017), "How do top- and bottom-performing companies differ in using business analytics?", Journal of Enterprise Information Management, Vol. 30 No. 6, pp. 874-892, doi: 10.1108/JEIM-04-2016-0080.

Cheah, S. and Wang, S. (2017), "Big data-driven business model innovation by traditional industries in the Chinese economy", Journal of Chinese Economic and Foreign Trade Studies, Vol. 10 No. 3, pp. 229-251, doi: 10.1108/JCEFTS-05-2017-0013.

Chesbrough, H., (2010), "Business model innovation: opportunities and barriers", Long Range Planning, Vol. 43 Nos 2/3, pp. 354-363, doi: 10.1016/j.lrp.2009.07.010.

Chesbrough, H. and Rosenbloom, R., (2002), "The role of the business model in capturing value from innovation: evidence from xerox corporation's technology spin-off companies", Industrial and Corporate Change, Vol. 11 No. 3, pp. 529-555.

Eisenhardt, K.M. and Graebner, M.E., (2007), "Theory building from cases: opportunities and challenges", Academy of Management Journal, Vol. 50 No. 1, pp. 25-32, doi: 10.5465/ AMJ.2007.24160888.

Erevelles, S., Fukawa, N. and Swayne, L., (2016), "Big data consumer analytics and the transformation of marketing”, Journal of Business Research, Vol. 69 No. 2, pp. 897-904, doi: 10.1016/j. jbusres.2015.07.001.

Favaretto, M., De Clercq, E., Schneble, C.O. and Elger, B.S., (2020), "What is your definition of big data? Researchers' understanding of the phenomenon of the decade", PLoS One, Vol. 15 No. 2, doi, doi: 10.1371/journal.pone.0228987.

Gawin, B. and Marcinkowski, B., (2017a), "From service-driven to data-driven: study design for modern facility management”, in Kowal, J., Kuzio, A., Makio, J., Paliwoda-Pekosz, G., Soja, P. and Sonntag, R. (Eds), ICT Management for Global Competitiveness and Economic Growth in Emerging Economies (ICTM), University of Wroclaw, Wroclaw, pp. 215-223.

Gawin, B. and Marcinkowski, B. (2017b), "Business intelligence in facility management: determinants and benchmarking scenarios for improving energy efficiency", Information Systems Management, Vol. 34 No. 4, pp. 347-358, doi: 10.1080/10580530.2017.1366219.

Gerring, J., (2004), "What is a case study and what is it good for?", American Political Science Review, Vol. 98 No. 2, pp. 341-354.

Gunawong, P. and Gao, P., (2017), "Understanding e-Government failure in the developing country context: a process-oriented study", Information Technology for Development, Vol. 23 No. 1, pp. 153-178, doi: 10.1080/02681102.2016.1269713.

Hartmann, P., Zaki, M., Feildman, N. and Neely, A., (2016), "Big data for big business? A taxonomy of data-driven business models used by start-up firms", International Journal of Operations and Production Management, Vol. 36 No. 10, pp. 1382-1406, doi: 10.1108/IJOPM-02-2014-0098.

IFMA (2012), "What is facility management?", available at: www.ifma.org/about/what-is-facilitymanagement (accessed 05 August 2020).

Jensen, P.A. (2011), “Organisation of facilities management in relation to core business", Journal of Facilities Management, Vol. 9 No. 2, pp. 78-95, doi: 10.1108/14725961111128443. 
Johnson, M., Christensen, C. and Kagermann, H. (2008), "Reinventing your business model", Harvard Business Review, Vol. 86 No. 12, pp. 57-68.

Keszey, T. (2017), "Information systems in transition economies: does ownership matter?", Information Systems Management, Vol. 34 No. 1, pp. 65-84, doi: 10.1080/10580530.2017.1254456.

Konanahalli, A., Oyedele, L., Marinelli, M., Selim, G., Eriksson, C. and Pitman, K. (2018), Big Data: A New Revolution in the UK Facilities Management Sector, RICS, London.

Kraus, S., Palmer, C., Kailer, N., Kallinger, F. and Spitzer, J. (2019), "Digital entrepreneurship", International Journal of Entrepreneurial Behavior and Research, Vol. ahead-of-print No. aheadof-print, pp. 353-375, doi: 10.1108/IJEBR-06-2018-0425.

Lindgardt, Z., Reeves, M., Stalk, G. and Deimler, M.S. (2009), Business Model Innovation. When the Game Gets Tough, Change the Game, the Boston Consulting Group, Boston, MA.

Liu, P. and Bell, R. (2019), "Exploration of the initiation and process of business model innovation of successful Chinese ICT enterprises", Journal of Entrepreneurship in Emerging Economies, Vol. 11 No. 4, pp. 515-536, doi: 10.1108/JEEE-09-2018-0094.

Lokitz, J. (2018), "Exploring big data business models and the winning value propositions behind them", available at: https://medium.com/@bmi_blog/exploring-big-data-business-models-thewinning-value-propositions-behind-them-f7b182458d98 (accessed 05 August 2020).

McAfee, A. and Brynjolfsson, E. (2012), "Big data: the management revolution”, Harvard Business Review, Vol. 90 No. 10, pp. 61-67.

Mandal, S. (2019), "The influence of big data analytics management capabilities on supply chain preparedness, alertness and agility: an empirical investigation", Information Technology and People, Vol. 32 No. 2, pp. 297-318, doi: 10.1108/itp-11-2017-0386.

Marchand, M. (2018), "New models in old frameworks? Contributions to the extension of international management theories through the analysis of emerging multinationals", International Journal of Emerging Markets, Vol. 13 No. 3, pp. 499-517, doi: 10.1108/ijoem-03-2016-0070.

Martínez-Alonso, R., Martínez-Romero, M. and Rojo-Ramírez, A., (2019), "The impact of technological innovation efficiency on firm growth: the moderating role of family involvement in management", European Journal of Innovation Management, Vol. 23 No. 1, pp. 134-155, doi: 10.1108/EJIM-09-2018-0210.

Mazzarol, T., Clark, D., Reboud, S. and Mamouni-Limnios, E. (2018), "Developing a conceptual framework for the co-operative and mutual enterprise business model", Journal of Management and Organization, Vol. 24 No. 4, pp. 551-581, doi: 10.1017/jmo.2018.29.

Mehdi, N. (2018), Big Data, Smart Cities, Intelligent Buildings - Surveying in a Digital World, RICS, London.

Molka-Danielsen, J., Engelseth, P. and Le, B.T.N. (2017), "Vendor-Managed inventory as data interchange strategy in the networked collaboration of a Vietnam ship parts supplier and its customers", Information Technology for Development, Vol. 23 No. 3, pp. 597-617, doi: 10.1080/ 02681102.2017.1328655.

Nardelli, G. and Rajala, R. (2018), "The evolution of facility management business models in supplierclient relationships", Journal of Facilities Management, Vol. 16 No. 1, pp. 38-53, doi: 10.1108/JFM05-2017-0022.

Osterwalder, A. and Pigneur, Y. (2010), "Business model generation", A Handbook for Visionaries, Game Changers, and Challengers, Wiley, Hoboken, NJ.

Pang, C., Wang, Q., Li, Y. and Duan, G. (2019), "Integrative capability, business model innovation and performance: contingent effect of business strategy", European Journal of Innovation Management, Vol. 22 No. 3, pp. 541-561, doi: 10.1108/EJIM-09-2018-0208.

Rotella, P. (2012), "Is data the new oil?", available at: www.forbes.com/sites/perryrotella/2012/04/02/isdata-the-new-oil (accessed 05 August 2020). 
Smith, D., Lyle, S., Berry, A., Manning, N., Zaki, M. and Neely, A. (2015), "Internet of animal health things (IoAHT)", Opportunities and Challenges, University of Cambridge, Cambridge.

Wang, X. and Xu, M. (2018), "Examining the linkage among open innovation, customer knowledge management and radical innovation: the multiple mediating effects of organizational learning ability", Baltic Journal of Management, Vol. 13 No. 3, pp. 368-389, doi: 10.1108/BJM-04-20170108.

Ware, J., Harris, R., Bowen, M. and Carder, P. (2017), Raising the Bar: From Operational Excellence to Strategic Impact in FM, RICS, London.

Yin, R.K. (2017), Case Study Research and Applications: Design and Methods, (6th ed.), SAGE Publications, London.

Zaki, M., Lillegraven, T. and Neely, A. (2015), Moving towards a Data-Driven Business Model (DDBM) in the Online Newspaper Publishing Industry, University of Cambridge, Cambridge.

Zott, C., Amit, R. and Massa, L. (2011), "The business model: recent developments and future research", Journal of Management, Vol. 37 No. 4, pp. 1019-1042, doi: 10.1177/0149206311406265.

\section{Corresponding author}

Bartlomiej Gawin can be contacted at: bartlomiej.gawin@ug.edu.pl

For instructions on how to order reprints of this article, please visit our website: 